\title{
Urea as a Cocrystal Former-Study of 3 Urea Based Pharmaceutical Cocrystals
}

\author{
Fucheng Leng, Koen Robeyns (D) and Tom Leyssens * (D) \\ Institute of Condensed Matter and Nanosciences, Université Catholique de Louvain, B-1348 Louvain-La-Neuve, \\ Belgium; leng.fucheng@uclouvain.Be (F.L.); koen.robeyns@uclouvain.be (K.R.) \\ * Correspondence: tom.leyssens@uclouvain.be
}

Citation: Leng, F.; Robeyns, K.; Leyssens, T. Urea as a Cocrystal Former-Study of 3 Urea Based Pharmaceutical Cocrystals. Pharmaceutics 2021, 13, 671. https://doi.org/10.3390/ pharmaceutics 13050671

Academic Editors: Saeed Shirazian and Rahamatullah Shaikh

Received: 13 April 2021

Accepted: 27 April 2021

Published: 7 May 2021

Publisher's Note: MDPI stays neutral with regard to jurisdictional claims in published maps and institutional affiliations.

Copyright: (c) 2021 by the authors. Licensee MDPI, Basel, Switzerland. This article is an open access article distributed under the terms and conditions of the Creative Commons Attribution (CC BY) license (https:/ / creativecommons.org/licenses/by/ $4.0 /)$.
Abstract: Cocrystallization is commonly used for its ability to improve the physical properties of APIs, such as solubility, bioavailability, compressibility, etc. The pharmaceutical industry is particularly interested in those cocrystals comprising a GRAS former in connection with the target API. In this work, we focus on the potential of urea as a cocrystal former, identifying three novel pharmaceutical cocrystal systems with catechin, 3-hydroxyl-2-naphthoic and ellagic acid. Interestingly, the stability of catechin under high humidity or high temperature environment is improved upon cocrystallization with urea. Moreover, the solubility of ellagic acid is improved about 17 times. This work displays the latent possibility of urea in improving the physical property of drug molecules using a cocrystallization approach.

Keywords: cocrystal; urea; stability improvement; catechin; ellagic acid; 3-hydroxyl-2-naphthoic acid

\section{Introduction}

Cocrystals have drawn increasing attention in recent years due to their ability to improve physical properties of active pharmaceutical ingredients (APIs) without changing the chemical structure of the original drug [1-4]. Although still in debate, a well-accepted definition describes cocrystals as "solids that are crystalline single-phase materials composed of two or more different molecules and/or ionic compounds generally in a stoichiometric ratio which are neither solvates nor simple salts" [5]. More specifically, pharmaceutical cocrystals combine a drug compound and a pharmaceutically acceptable coformer. There have been eight pharmaceutical cocrystals marketed up to date, with an even more important number undergoing clinical trials [6].

Indexed as a GRAS (General Regarded As Safe) compound, urea is an excellent choice of coformer from the pharmaceutical (safe) and economic (inexpensive) point of view. High water solubility coformers in general increase the solubility of the API when the cocrystal is formed $[2,7,8]$. Urea cocrystals are therefore expected to strongly impact the API solubility. Urea furthermore has functional groups frequently encountered in cocrystal hydrogen bonding patterns, and therefore forms an ideal candidate for co-crystal screening $[9,10]$. Various contributions already show the potential of urea for the improvement of physical properties compared to the original API [11-14]. Urea cocrystals raised the solubility of agomelatine 2.2 times [15]. Urea also improved the intrinsic dissolution rate of bumetanide [11], febuxostat [13] and niclosamide [14] in a variety of solvents.

We here present, three novel urea comprising pharmaceutical cocrystals with catechin, 3-hydroxyl-2-naphthoic acid and ellagic acid, all of which show interesting bioactivity. Specifically, ellagic acid is widely used in food and pharmaceutical industry owing to its antioxidant and anti-inflammatory effect $[16,17]$. The anti-diabetic effect of 3-hydroxyl-2naphthoic acid has also been proved by previous reports [18]. Catechin is a flavanol which has been effectiveness as an antioxidant, and for improvement of the immune system response [19-22]. In this work we show how cocrystallization with urea, leads to a 17-fold solubility increase of ellagic acid, as well as an improvement of the physical stability of 
catechin. This work therefore further underlines the potential of urea for the improvement of physical properties of API through cocrystallization.

\section{Materials and Methods}

Materials. Catechin (98\%) and 3-hydroxyl-2-naphthoic acid (98\%) were bought from sigma-Aldrich, St. Louis, MO, USA. Ellagic acid (97\%) was bought from Alfa Aesar, Haverhill, MA, USA. Urea was bought from Merck. Catechin hydrate is obtained by slurring catechin in water for 2 days, apart from that, all reagents were used as received.

Cocrystal screen. In a typical cocrystal screening experiment, $0.25 \mathrm{mmol}$ urea and an equimolar amount of API are placed in an Eppendorf adding one stainless steel ball. After that, grinding was performed using a RETSCH Mixer Mill MM 400 with a beating frequency of $30 \mathrm{~Hz}$ for $90 \mathrm{~min}$. Subsequently, the PXRD of the ground material is compared to that of the parent compounds. Upon apparition of novel peaks, grinding is performed under various ratios as well. When neat grinding did not lead to a full transformation, liquid assisted grinding was performed in parallel, adding $20 \mu \mathrm{L}$ of solvent to the initial mixture of urea and target compound prior to grinding (solvents include methanol, ethanol, water, acetonitrile and isopropanol).

Mechanical synthesis of cocrystals. The urea:ellagic acid cocrystal (UE) can be obtained by liquid assisted grinding of $30 \mathrm{mg}$ urea and $75 \mathrm{mg}$ ellagic acid (2:1 molar ratio) using 20 $\mu \mathrm{L}$ of water or isopropanol. The urea:3-hydroxyl-2-naphthoic acid cocrystal (UH) as well as urea:catechin cocrystal (UC) can be obtained by dry grinding in a 1:1 molar ratio.

Single crystal growth. Methanol is added in a drop-wise manner to a vial containing $25 \mathrm{mg}$ of catechin and $24 \mathrm{mg}$ urea (1:5 molar ratio) until full dissolution is achieved. After that, the solution is left to evaporate. After one week, UC crystals are obtained of sufficient quality for SC-XRD. In a similar approach, single crystals of UH are obtained by evaporating an undersaturated methanol solution of urea and 3-hydroxyl-2-naphthoic acid (in a 1:3 molar ratio).

Powder X-ray diffraction and variable temperature X-ray powder diffraction (VT$X R P D)$. Powder $X$-ray diffraction of all samples are conducted on a Siemens D5000 diffractometer equipped with a $\mathrm{Cu} X$-ray source operating at $40 \mathrm{KV}$ and $40 \mathrm{~mA}(\lambda=1.5418 \AA)$ from 2 to 50 degree at the rate of 0.6 degree per minute. VT-XRPD of catechin hydrate is collected on a PANalytical X'Pert PRO automated diffractometer from 3 to 40 degree, equipped with an X'Celerator detector and an Anton Paar TTK 450 system for measurements at controlled temperature. Data were collected in open air in Bragg-Brentano geometry, using $\mathrm{Cu}-\mathrm{K} \alpha$ radiation without a monochromator.

Structure Determination. Single crystal diffraction data for UC and UH were collected on a MAR345 image plate detector using Mo K $\alpha$ radiation $(\lambda=0.71073 \AA)$, generated by a Rigaku Ultra X18S rotating anode (Xenocs fox3d mirrors). For UC the crystal was flash frozen at $150 \mathrm{~K}$ in a $\mathrm{N}_{2}$ flow prior to data collection. Data integration and reduction was performed by CrystAlisPro [23] and the implemented absorption correction was applied. Structure solution was performed by the dual-space algorithm in SHELXT [24] and the structure was further refined against $F^{2}$ using SHELXL2014/7. All non-hydrogen atoms were refined anisotropically and hydrogen atoms were placed at calculated positions with temperature factors set at $1.2 \mathrm{U}_{\mathrm{eq}}$ of the parent atoms ( $1.5 \mathrm{U}_{\mathrm{eq}}$ for methyl and $\mathrm{OH}$ hydrogens).

For UE the structure was solved from powder diffraction measured on a STOE STADI $\mathrm{P}$ diffractometer using monochromated $\mathrm{Cu} \mathrm{K} \alpha 1$ radiation in transmission mode (with the sample placed between zero scattering foils). Unit cell determination was performed by DICVOL and the structure was solved by DASH [25], the structure was subsequently optimized by Rietveld refinement in Fullprof [26]. The Rietveld profile is shown in Figure S15.

Thermogravimetric Analysis (TGA). Typically, the TGA analyses of all samples are performed from 30 to $450{ }^{\circ} \mathrm{C}$ using a heating rate of $5{ }^{\circ} \mathrm{C} / \mathrm{min}$ with a continuous nitrogen flow of $50 \mathrm{~mL} / \mathrm{min}$, on a Mettler Toledo TGA/SDTA851e.

Differential Scanning Calorimetry (DSC). DSC measurements are performed on a TA DSC2500. Deposited in an aluminum Tzero pans with punctured hermetic lid, samples 
were heated from $20^{\circ} \mathrm{C}$ up to $240{ }^{\circ} \mathrm{C}$ using a heating rate of $2{ }^{\circ} \mathrm{C} /$ min under a $50 \mathrm{~mL} / \mathrm{min}$ continuous nitrogen flow.

Congruence experiments. Stoichiometric amounts of urea and API were added to $1 \mathrm{~mL}$ of solvent until dissolution no longer occurred and a suspension was obtained. After that, ground traces of cocrystal material were added to the suspension as seed material. After 3 days of slurrying at room temperature, the suspension was filtered and the solid analyzed by PXRD.

Solubility measurement. The solubility measurement is conducted in ethanol at room temperature. An excess amount of solid is added to $2 \mathrm{~mL}$ of ethanol and the suspension is left to slurry for 2 days reaching saturation. After that, the suspension is filtered, and the filtrate weighed and left for evaporation. Weighing the recovered solids, allows determining the amount of solvent as well as solid present in the filtrate, and hence the solubility.

\section{Results}

\subsection{Cocrystal Screening}

As our main goal was to show the potential of urea as a pharmaceutical cocrystal former, a screen involving 62 APIs was performed (Table S1). Seven positive hits were identified in agreement with literature reported success rates of about $10 \%$ (Figure 1) [27]. From this data, APIs containing a phenol group have a higher likelihood of forming a cocrystal with urea. Four cocrystals were already reported in literature (Figures S1-S4) (theophylline, nicotinamide, salicylic acid, and hydroquinone) [28-30]. We report here three new cocrystal systems with catechin, ellagic acid, and 3-hdyroxyl-2-naphthoic acid, which are discussed in detail.<smiles>Oc1cc(O)c2c(c1)O[C@H](c1ccc(O)c(O)c1)C[C@H]2O</smiles>

Catechin<smiles>O=C(O)c1ccccc1O</smiles>

Salicylic acid<smiles></smiles>

Ellagic acid<smiles>NC(=O)c1cccnc1</smiles>

nicotinamide<smiles>Cn1c(=O)c2[nH]cnc2n(C)c1=O</smiles>

theophylline<smiles>O=C(O)c1cc2ccccc2cc1O</smiles>

3-hydroxyl-2-naphthoic acid<smiles>Oc1ccc(O)cc1</smiles>

hydroquinone

Figure 1. Chemical structure of the active pharmaceutical ingredients used in our screen which form cocrystals with urea.

\subsection{Urea-Catechin Cocrystal (UC)}

Urea and catechin cocrystallize in the monoclinic $P 2_{1}$ space group (Table 1 ). The unit cell contains two urea and two catechin molecules. As a hydrogen bond acceptor, the oxygen atom of each urea molecule is connected to a $\mathrm{N}-\mathrm{H}$ group of a second urea molecule and to a phenolic hydroxyl of catechin. Furthermore, all hydroxyl groups are engaged in hydrogen bonds with hydroxyl groups of neighboring catechin molecules (Figure 2). 
Table 1. SC-XRD crystallographic data for the UC and UH cocrystals.

\begin{tabular}{|c|c|c|}
\hline Compound & UC Cocrystal & UH Cocrystal \\
\hline Formula & $\mathrm{C}_{16} \mathrm{H}_{18} \mathrm{~N}_{2} \mathrm{O}_{7}$ & $\mathrm{C}_{12} \mathrm{H}_{12} \mathrm{~N}_{2} \mathrm{O}_{4}$ \\
\hline$D_{\text {calc. }} / \mathrm{g} \mathrm{cm}^{-3}$ & 1.544 & 1.398 \\
\hline$m / \mathrm{mm}^{-1}$ & 0.123 & 0.107 \\
\hline Formula Weight & 350.32 & 248.24 \\
\hline Colour & Brown & colourless \\
\hline Shape & needle & $\operatorname{rod}$ \\
\hline Size $/ \mathrm{mm}^{3}$ & $0.35 \times 0.02 \times 0.02$ & $0.30 \times 0.10 \times 0.05$ \\
\hline $\mathrm{T} / \mathrm{K}$ & $150(2)$ & 293(2) \\
\hline Crystal System & monoclinic & monoclinic \\
\hline Space Group & $P 2_{1}$ & $\mathrm{C} 2 / \mathrm{c}$ \\
\hline$a / \AA$ & $10.7771(12)$ & $24.353(2)$ \\
\hline$b / \AA$ & $5.0024(5)$ & $5.0996(4)$ \\
\hline$c / \AA$ & $14.960(3)$ & 20.7056(19) \\
\hline$\alpha /^{\circ}$ & 90 & 90 \\
\hline$\beta /^{\circ}$ & $110.849(17)$ & 113.490(11) \\
\hline$\gamma /{ }^{\circ}$ & 90 & 90 \\
\hline $\mathrm{V} / \AA^{3}$ & $753.68(19)$ & $2358.3(4)$ \\
\hline$Z$ & 2 & 8 \\
\hline$Z^{\prime}$ & 1 & 1 \\
\hline Wavelength/A & 0.71073 & 0.71073 \\
\hline Radiation type & $\mathrm{MoK}_{\alpha}$ & $\mathrm{MoK}_{\alpha}$ \\
\hline Measured Refl's. & 3867 & 8859 \\
\hline Indep't Refl's & 2127 & 2341 \\
\hline Refl's I $\geq 2 s(\mathrm{I})$ & 1217 & 1938 \\
\hline$R_{\text {int }}$ & 0.1191 & 0.0365 \\
\hline GooF & 1.026 & 1.063 \\
\hline$w R_{2}$ (all data) & 0.1510 & 0.1192 \\
\hline$w R_{2}$ & 0.1240 & 0.1125 \\
\hline$R_{1}$ (all data) & 0.1472 & 0.0511 \\
\hline$R_{1}$ & 0.0775 & 0.0421 \\
\hline
\end{tabular}


(a)

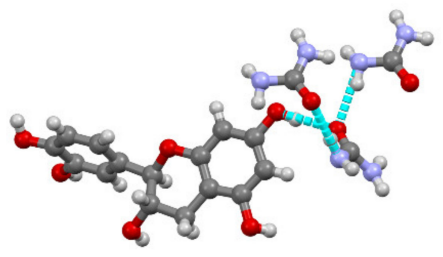

(b)

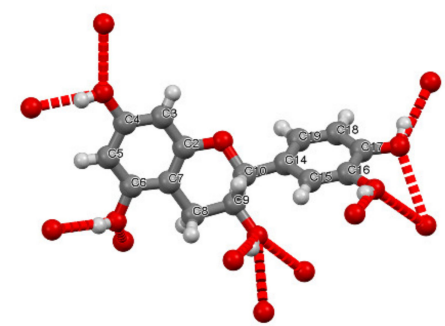

(c)

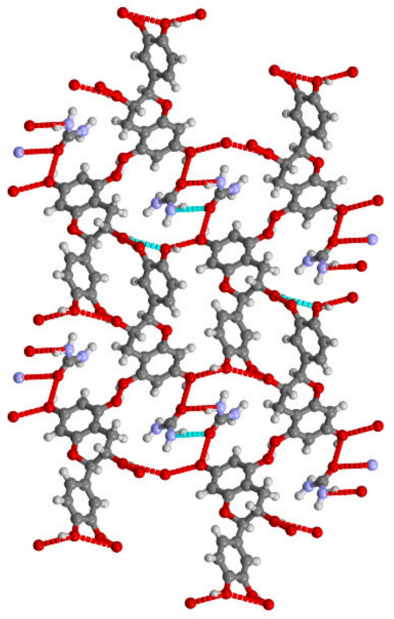

Figure 2. (a) Hydrogen bonding around a urea molecule in the UC cocrystal. (b) Hydrogen bonding around a catechin molecule in the cocrystal. (c) View along the a axis.

Figure 3 shows a PXRD overlay of the ground and starting materials (catechin is not displayed because the used catechin was amorphous), as well as the pattern simulated from the single crystal structure. As shown in this figure, the ground material matches the one from single crystal analysis, corresponding to the 1:1 cocrystal.

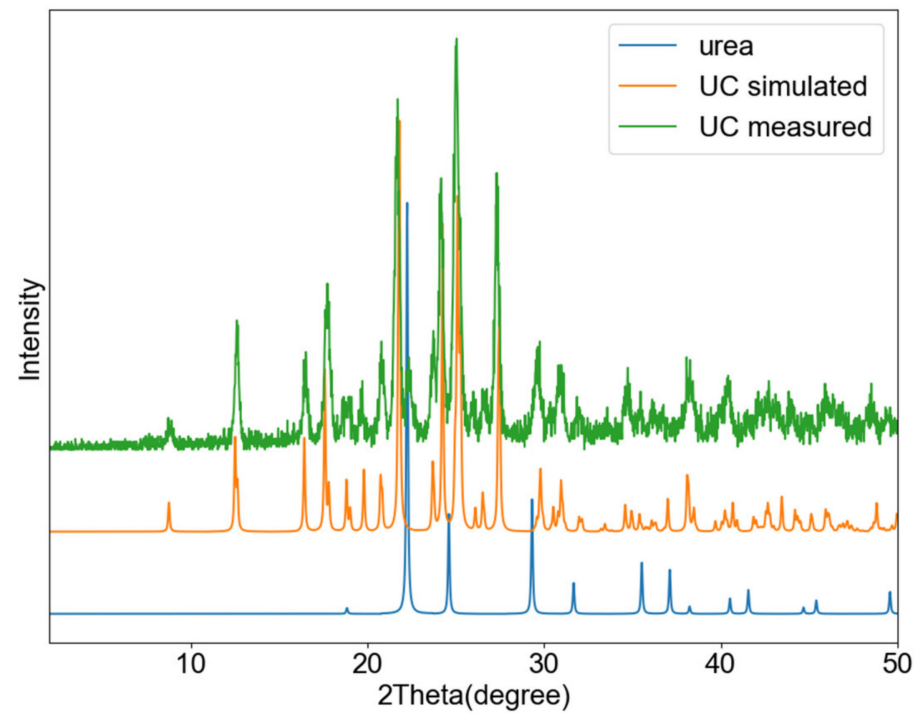

Figure 3. PXRD profiles of UC obtained by grinding (green), the simulated pattern of the UC cocrystal (orange), and urea (blue).

Urea shows a single melting point with onset at $134{ }^{\circ} \mathrm{C}$ immediately followed by a degradation as illustrated by the TGA analysis, similar to previous report [31]. The UC cocrystal shows a melting temperature of $176^{\circ} \mathrm{C}$ with a corresponding heat of fusion of $162.78 \mathrm{~J} / \mathrm{g}$ (Figure 4), which is followed by a degradation endotherm. Comparing the UC and the amorphous catechin material in terms of humidity stability, one notices the UC cocrystal to remain stable at $75 \% \mathrm{RH}$ at $25^{\circ} \mathrm{C}$ for a period of two weeks (Figure S5), whilst storing the amorphous material, leads to crystalline catechin hydrate under these conditions. Catechin hydrate in turn starts losing water at temperatures above $50{ }^{\circ} \mathrm{C}$ (Figure S6), transforming into the amorphous phase upon dehydration (Figure S7). Cocrystallization with urea, therefore, leads to a solid form of catechin which is much less moisture or thermo-sensitive. 


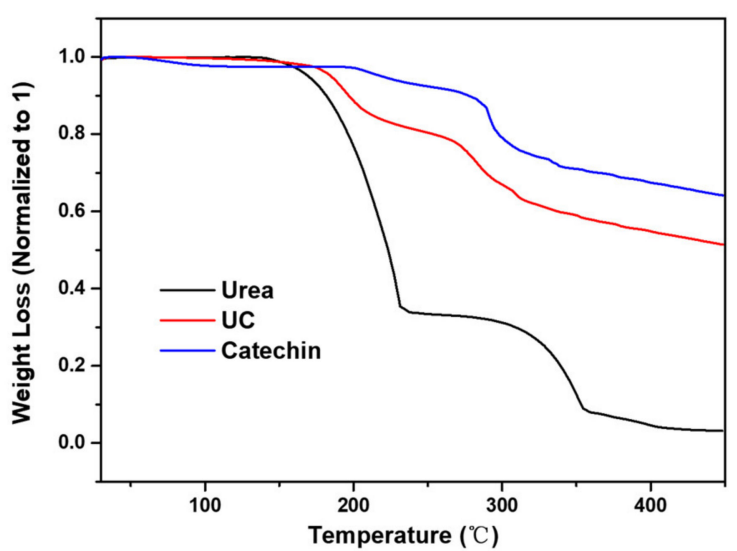

(a)

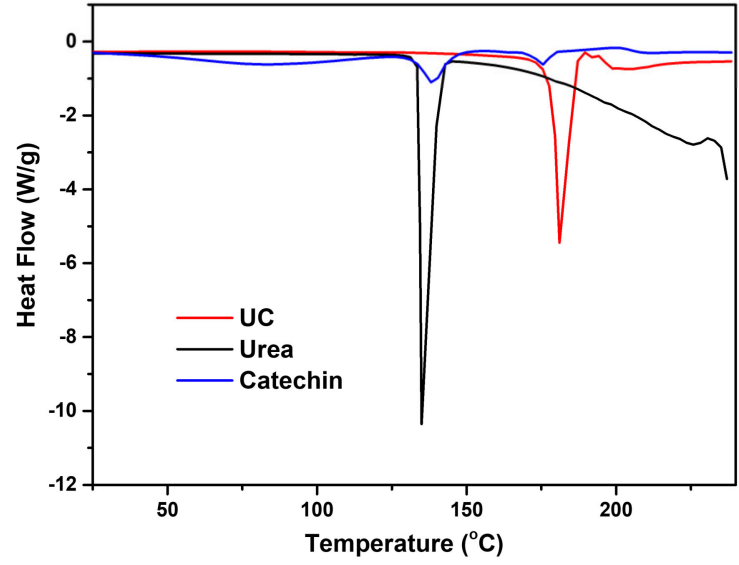

(b)

Figure 4. (a) TGA curves of urea, catechin and UC. (b) DSC curves of urea, catechin and UC.

\subsection{Urea-3-Hydroxyl-2-Naphtoic Acid (UH)}

Urea and 3-hydroxyl-2-naphthoic acid crystallize in the monoclinic $C 2 / c$ space group in a 1:1 ratio. The carboxylic acid of 3-hydroxyl-2naphthoic acid, is connected to the amide group of urea through an amide-acid hetero-synthon. The phenyl hydroxyl forms an intramolecular hydrogen bond, as well as an intermolecular hydrogen bond with urea (Figure 5). Other hydrogen bonding patterns involve different urea molecules and are of the $\mathrm{C}=\mathrm{O}-\mathrm{H}-\mathrm{N}$ type (Figure 5).

(a)

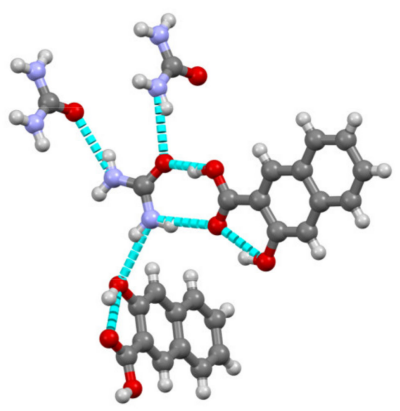

(b)
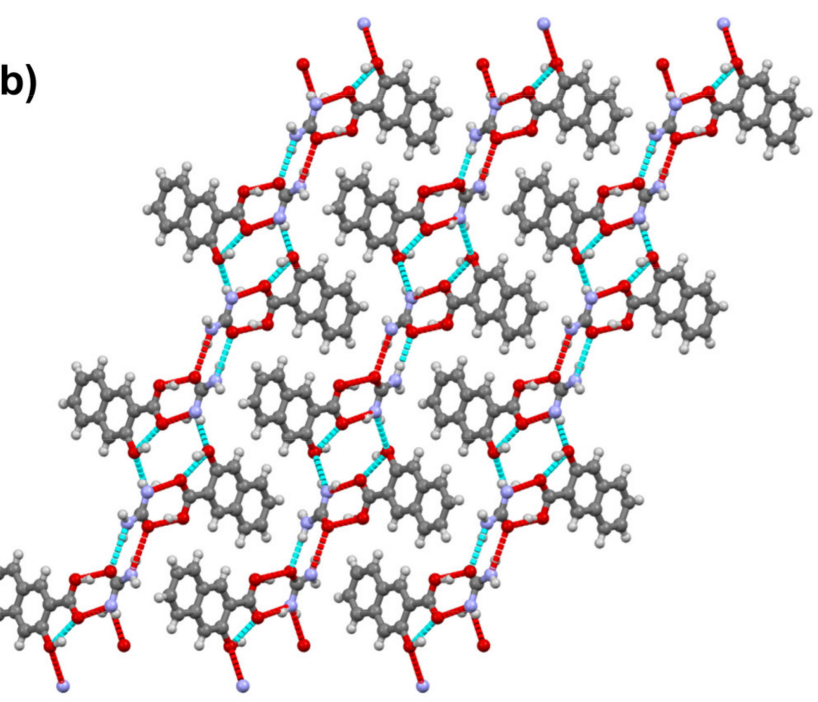

Figure 5. (a) Hydrogen bonds in UH. (b) View of crystal structure of UH along the b axis.

Figure 6 shows a PXRD overlay of the ground and starting materials, as well as the simulated pattern from the single crystal data. As shown in this figure, the ground material matches the single crystal phase, corresponding to a 1:1 cocrystal. 


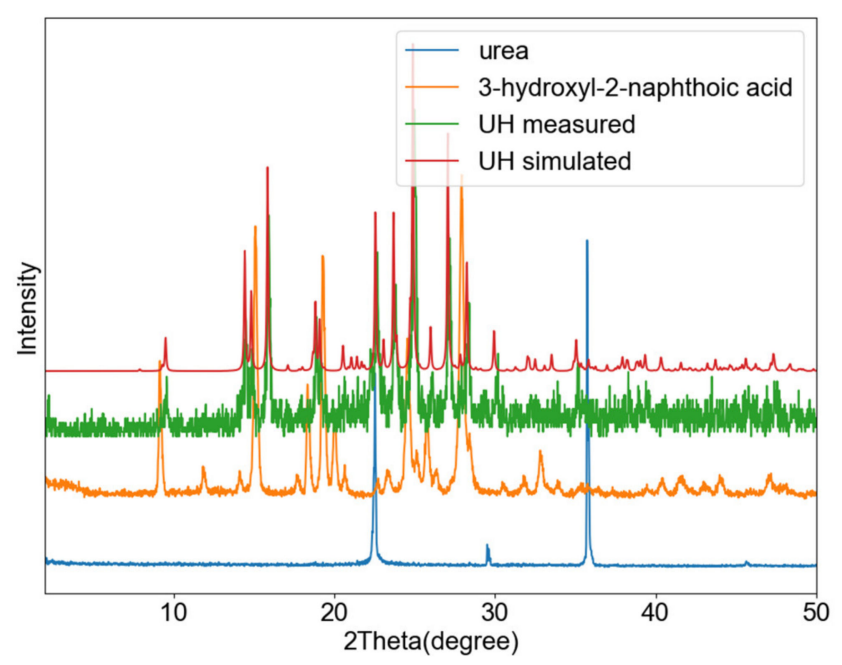

Figure 6. PXRD profiles of urea (blue), UH co-crystal obtained by grinding (green), the simulated UH pattern (red) and the experimental 3-hydroxyl-2-naphthoic acid pattern (orange).

Further, 3-hydroxyl-2-naphthoic acid shows a single melting point with onset at $218{ }^{\circ} \mathrm{C}$ and an associated $173.3 \mathrm{~J} / \mathrm{g}$ heat of fusion. The cocrystal in turn shows a single melting temperature at $155{ }^{\circ} \mathrm{C}$ with a heat of fusion $156.78 \mathrm{~J} / \mathrm{g}$ followed by immediate degradation. As common for cocrystals, this melting point lies between that of both parent compounds. TGA confirms degradation upon melting for all phases (Figure 7).

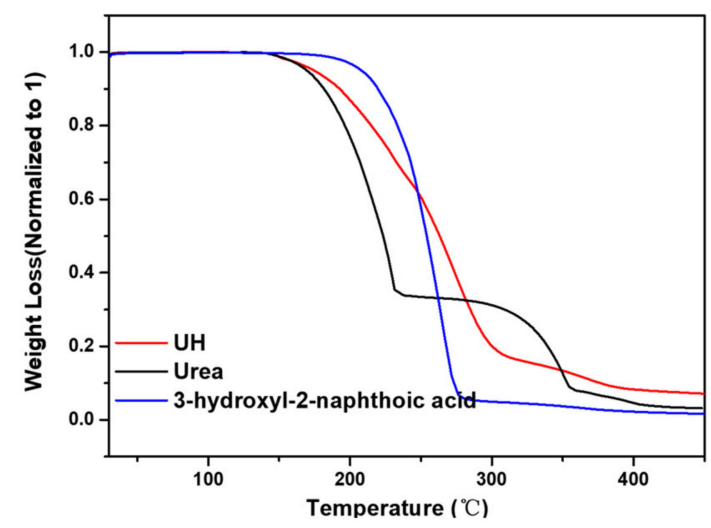

(a)

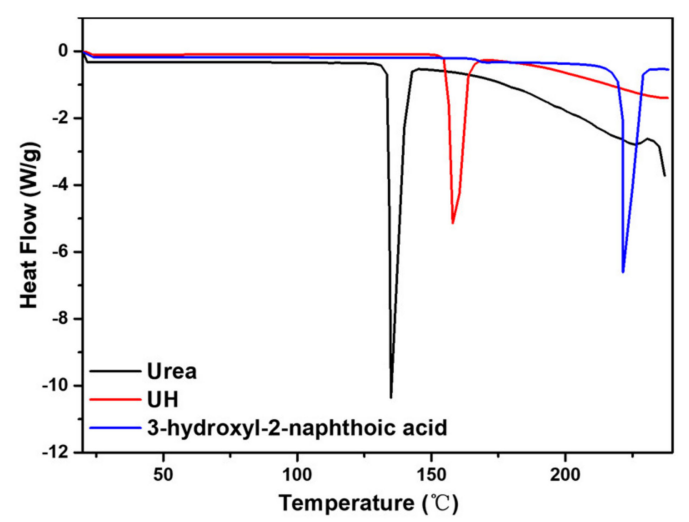

(b)

Figure 7. (a) TGA curves of urea, catechin and UC. (b) DSC curves of urea, catechin and UC.

\subsection{Urea-Ellagic Acid (UE)}

The UE cocrystal can be obtained by liquid assisted grinding of two equivalents of urea and one equivalent of ellagic acid using water (Figure 8). Grinding a 1:1 ratio, leads to cocrystal material with excess amount of ellagic acid. As attempts at growing a single crystal failed, the structure was resolved from the powder pattern. Urea and ellagic acid cocrystalize in the $P-1$ space group, with two urea and one ellagic acid molecule in the unit cell (Table S2). Ellagic acid is found on a crystallographic inversion center. For ellagic acid, the oxygen atoms in the ester group of ellagic acid serve as hydrogen bond acceptor, connecting to amide groups from urea molecules. On the other hand, the phenolic hydroxyl groups in ellagic acid serve as hydrogen bond donor to the carbonyl oxygen of a urea molecule (Figure 9). 


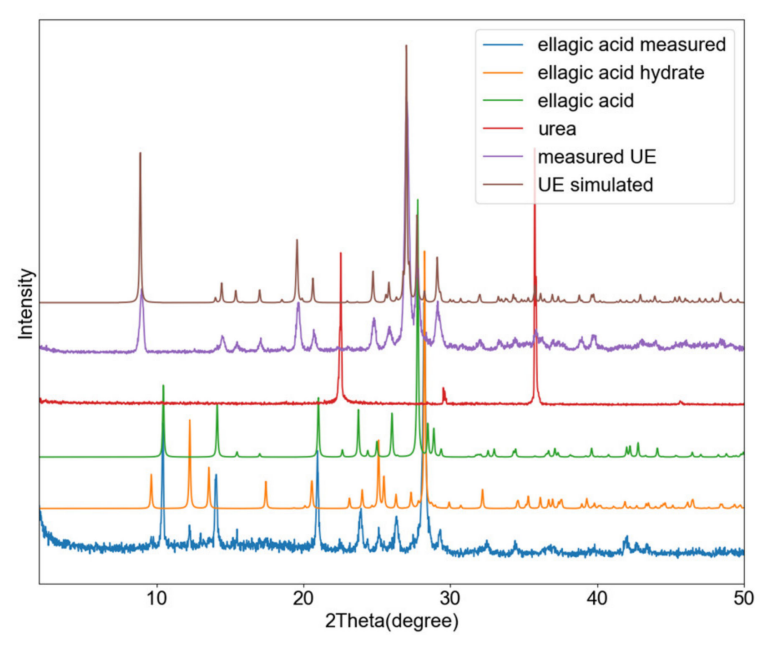

Figure 8. PXRD profiles of ellagic acid (blue), simulated ellagic acid hydrate (orange), simulated ellagic acid (green), urea (red), UE co-crystal obtained by grinding (purple), the simulated UH pattern (brown).

(a)

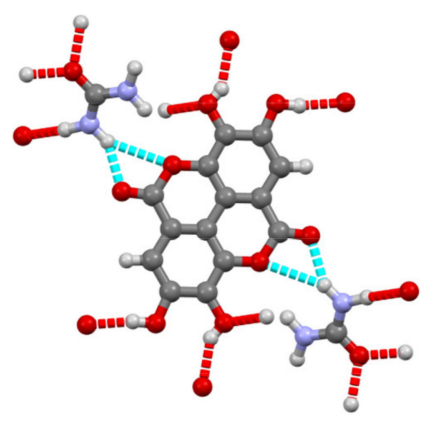

(b)

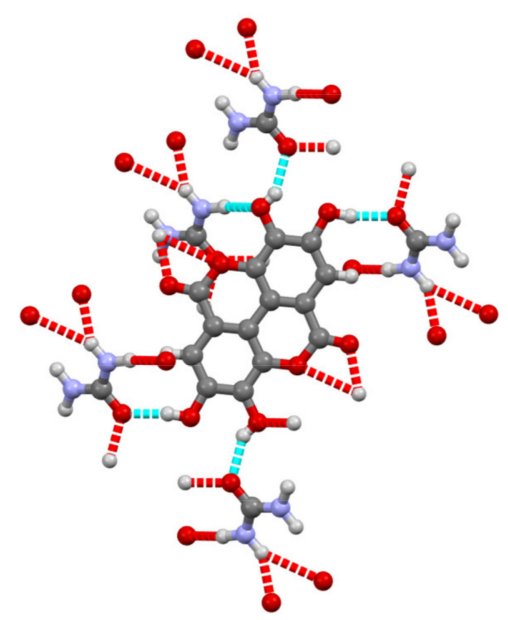

Figure 9. (a) Hydrogen bonds in UE between urea amide group and ellagic acid carbonyl group. (b) Hydrogen bonds formed by the phenol group in UE.

Thermal analysis of ellagic acid showed our initial powder to contain a mixture of the hydrate and anhydrate phase as shown in Figure 9. TGA of ellagic acid shows a mass loss of $2.5 \%$ at $103{ }^{\circ} \mathrm{C}$, suggesting a quarter of ellagic acid used here is under the dihydrate form. DSC confirms this water loss. Ellagic acid has a reported melting temperature of $350{ }^{\circ} \mathrm{C}$ [32]. The co-crystal shows a single endotherm peak at $222^{\circ} \mathrm{C}$, corresponding to the melting point of the cocrystal. TGA shows melting to be followed by immediate degradation (Figure 10). 


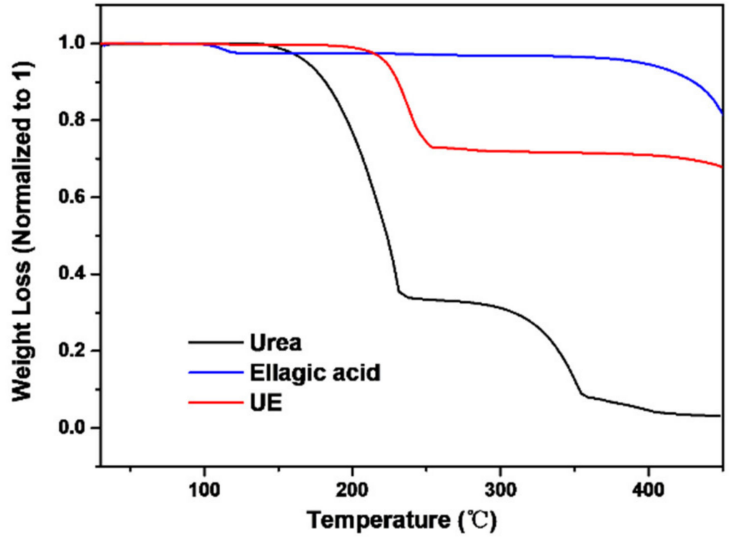

(a)

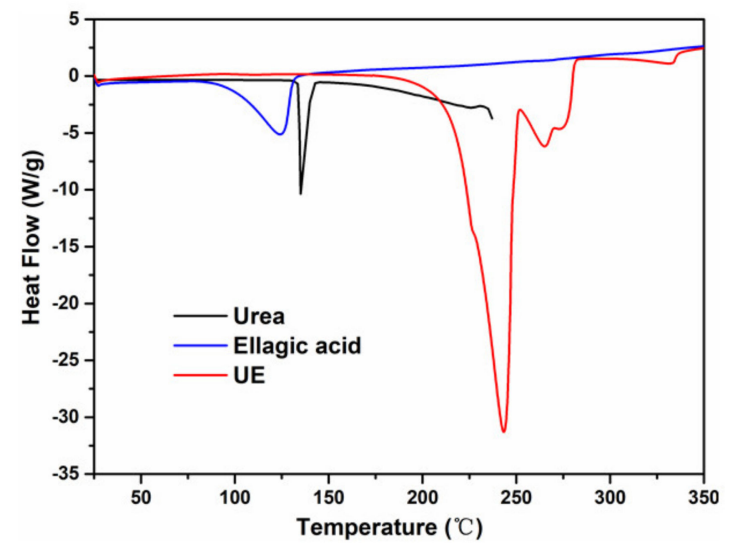

(b)

Figure 10. (a) TGA curves of urea, ellagic acid and UE. (b) DSC curves of urea, ellagic acid and UE.

\subsection{Solution Behavior}

The solution behavior of the novel phases was evaluated in various solvents. Initially, the cocrystals were suspended in a solvent to evaluate their congruency. Congruency implies that stoichiometric amounts of the cocrystal components lead to the cocrystal as the only stable phase in suspension, while non-congruency means that one of the parent compounds crystallizes out (or a mixture of cocrystal and a parent compound). UH behaves congruently in ethanol, acetonitrile and isopropanol, whereas it is not congruent in water or methanol (Figure S8), with 3-hydroxyl-2-naphthoic acid crystallizing out. UE behaves congruently in methanol, ethanol, acetonitrile and isopropanol. In water, ellagic acid hydrate is obtained (Figure S9). UC crystalizes congruently in all organic solvents used here and incongruently in water, with catechin hydrate crystallizing out (Figure 11). In mixed water/methanol solvents, UC behaves congruently for solvent mixtures of 1:9 to $4: 6$ water/methanol ratios (Figure S10). When the water/methanol ratio varies from 5:5 to 6:4, a recently identified catechin methanol solvate-hydrate crystallizes out (catechin:water:methanol 2:2:1) (Figure S11) [33]. With an even higher water/methanol ratio, a PXRD profile different from any known form is obtained (Figures S12 and S13). Drying this phase under ambient conditions yields catechin hydrate, suggesting another solvate of catechin was likely obtained. Slurrying catechin on its own in water/methanol ratios from 7:3 to 9:1, only gives the catechin hydrate, which means urea likely plays a role in the stabilization of the yet unknown catechin solvate (Figure S14).

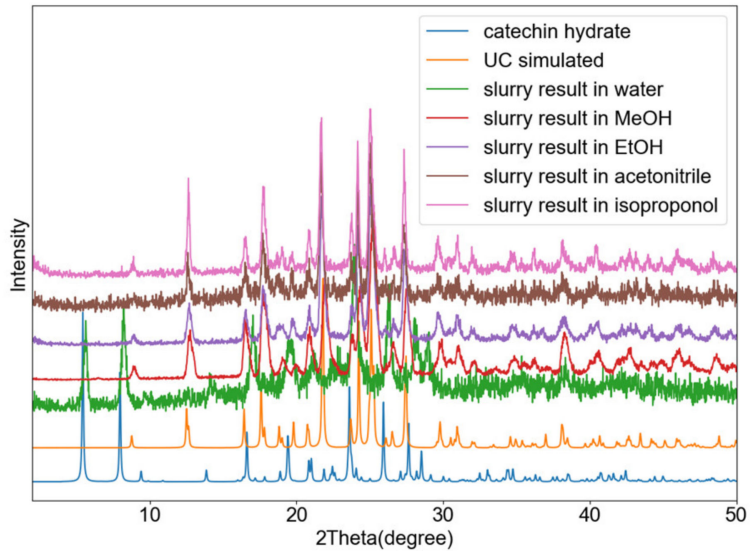

(a)

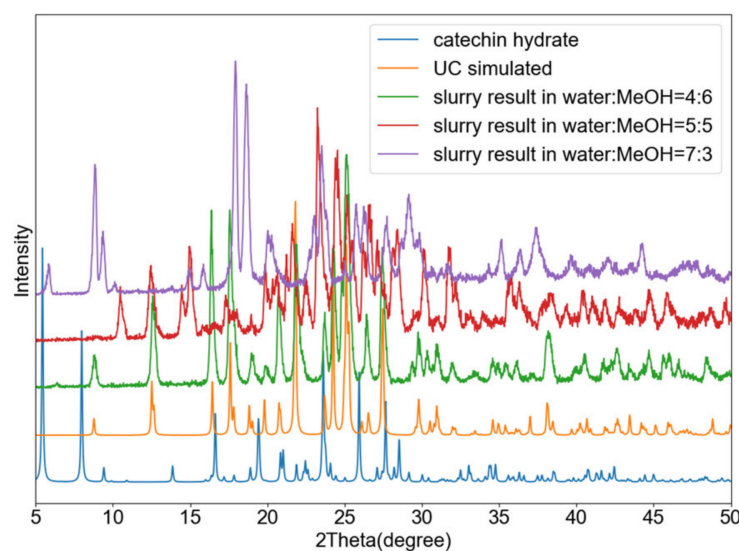

(b)

Figure 11. (a) PXRD profiles of congruence experiments results of UC in different solvents. (b) Various products obtained using different methanol/water ratio when suspending stoichiometric ratio of urea and catechin. 
As all three new cocrystals behave congruently in ethanol, solubility measurements were conducted in this solvent. For UC and UH cocrystal, a solubility of $0.595 \mathrm{~mol} / \mathrm{L}$ and $0.439 \mathrm{~mol} / \mathrm{L}$ is obtained, which is lower than that of the parent compound $(0.736 \mathrm{~mol} / \mathrm{L}$ and $0.599 \mathrm{~mol} / \mathrm{L}$ respectively). For ellagic acid, the behavior is inverted, with the solubility being raised from $0.52 \mathrm{mmol} / \mathrm{L}$ to $9.04 \mathrm{mmol} / \mathrm{L}$, showing the potential of cocrystallization to strongly impact the solubility behavior of poorly soluble drugs. Solubility of a cocrystal depends on the free energy of the novel cocrystal as well as the solution free energy of dissolved compounds and their solution interaction. Predicting this solubility merely on the structure is not feasible. The increase in solubility for ellagic acid is not surprising as the solubility of ellagic acid is extremely low. Very likely a variation of free energy of the solid structure as well as a positive interaction between both components in solution needs to be taken into account.

\section{Conclusions}

In this work, three novel cocrystals involving urea were identified, targeting catechin, ellagic acid, and 3-hydroxyl-2-naphthoic acid. Urea is a GRAS compound that is a promising coformer with a potential strong impact on the solubility of the target compound, as shown here for a 18-fold solubility increase for ellagic acid. Furthermore, we showed how the stability of the target compounds can be impacted and improved upon by cocrystallization with urea.

Supplementary Materials: The following are available at https://www.mdpi.com/article/10.3390/ pharmaceutics13050671/s1. Table S1: List of APIs used in cocrystal screen; Table S2: Crystallographic data of UE obtained from Rietveld refinement; Figures S1-S4: PXRD profiles of reported urea cocrystal; Figure S5: PXRD profiles of UC after humidity treatment; Figure S6: DSC curve of catechin hydrate; Figure S7: VT-PXRD profiles of catechin hydrate; Figures S8 and S9: Congruence experiments results of UH and UE; Figures S10-S12: Congruence experiment result of UC in methanol/water; Figure S13: PXRD profile of the new catechin hydrate; Figure S14: PXRD profiles of catechin slurry result in methanol/water; Figure S15: XRPD structure resolution data for the ellagic acid urea cocrystal.

Author Contributions: Conceptualization, T.L. and K.R.; methodology, T.L.; software, K.R.; validation, T.L., K.R. and F.L.; formal analysis, F.L.; investigation, F.L.; data curation, F.L.; writing—original draft preparation, F.L.; writing - review and editing, T.L. and K.R.; supervision, T.L. and K.R.; project administration, T.L.; funding acquisition, T.L. All authors have read and agreed to the published version of the manuscript.

Funding: F.L. was funded by Chinese Scholarship Council (CSC).

Institutional Review Board Statement: Not applicable.

Informed Consent Statement: Not applicable.

Data Availability Statement: Not applicable.

Conflicts of Interest: Authors declare no conflict of interest.

\section{References}

1. Sun, C.C. Cocrystallization for successful drug delivery. Expert Opin. Drug Deliv. 2013, 10, 201-213. [CrossRef]

2. Kuminek, G.; Cao, F.; Bahia de Oliveira da Rocha, A.; Goncalves Cardoso, S.; Rodriguez-Hornedo, N. Cocrystals to facilitate delivery of poorly soluble compounds beyond-rule-of-5. Adv. Drug Deliv. Rev. 2016, 101, 143-166. [CrossRef]

3. Bolla, G.; Nangia, A. Pharmaceutical cocrystals: Walking the talk. Chem. Commun. 2016, 52, 8342-8360. [CrossRef]

4. Karimi-Jafari, M.; Padrela, L.; Walker, G.M.; Croker, D.M. Creating Cocrystals: A Review of Pharmaceutical Cocrystal Preparation Routes and Applications. Cryst. Growth Des. 2018, 18, 6370-6387. [CrossRef]

5. Aitipamula, S.; Banerjee, R.; Bansal, A.K.; Biradha, K.; Cheney, M.L.; Choudhury, A.R.; Desiraju, G.R.; Dikundwar, A.G.; Dubey, R.; Duggirala, N.; et al. Polymorphs, Salts, and Cocrystals: What's in a Name? Cryst. Growth Des. 2012, 12, 2147-2152. [CrossRef]

6. Kavanagh, O.N.; Croker, D.M.; Walker, G.M.; Zaworotko, M.J. Pharmaceutical cocrystals: From serendipity to design to application. Drug Discov. Today 2019, 24, 796-804. [CrossRef] [PubMed]

7. Good, D.J.; Rodriíguez-Hornedo, N. Solubility Advantage of Pharmaceutical Cocrystals. Cryst. Growth Des. 2009, 9, 2252-2264. [CrossRef] 
8. Machado, T.C.; Kuminek, G.; Cardoso, S.G.; Rodriguez-Hornedo, N. The role of pH and dose/solubility ratio on cocrystal dissolution, drug supersaturation and precipitation. Eur. J. Pharm. Sci. 2020, 152, 105422. [CrossRef]

9. Desiraju, G.R. Supramolecular Synthons in Crystal Engineering-A New Organic Synthesis. Angew. Chem. Int. Ed. Engl. 1995, 34, 2311-2327. [CrossRef]

10. Gunawardana, C.A.; Aakeroy, C.B. Co-crystal synthesis: Fact, fancy, and great expectations. Chem. Commun. 2018, 54, 14047-14060. [CrossRef]

11. Allu, S.; Bolla, G.; Tothadi, S.; Nangia, A.K. Novel Pharmaceutical Cocrystals and Salts of Bumetanide. Cryst. Growth Des. 2019, 20, 793-803. [CrossRef]

12. Li, Z.; Li, M.; Peng, B.; Zhu, B.; Wang, J.-R.; Mei, X. Improving Compliance and Decreasing Drug Accumulation of Diethylstilbestrol through Cocrystallization. Cryst. Growth Des. 2019, 19, 1942-1953. [CrossRef]

13. Maddileti, D.; Jayabun, S.K.; Nangia, A. Soluble Cocrystals of the Xanthine Oxidase Inhibitor Febuxostat. Cryst. Growth Des. 2013, 13, 3188-3196. [CrossRef]

14. Sanphui, P.; Kumar, S.S.; Nangia, A. Pharmaceutical Cocrystals of Niclosamide. Cryst. Growth Des. 2012, 12, 4588-4599. [CrossRef]

15. Yan, Y.; Chen, J.-M.; Geng, N.; Lu, T.-B. Improving the Solubility of Agomelatine via Cocrystals. Cryst. Growth Des. 2012, 12, 2226-2233. [CrossRef]

16. Ceci, C.; Graziani, G.; Faraoni, I.; Cacciotti, I. Strategies to improve ellagic acid bioavailability: From natural or semisynthetic derivatives to nanotechnological approaches based on innovative carriers. Nanotechnology 2020, 31, 382001. [CrossRef]

17. Priyadarsini, K.I.; Khopde, S.M.; Kumar, S.S.; Mohan, H. Free radical studies of ellagic acid, a natural phenolic antioxidant. J. Agric. Food Chem. 2002, 50, 2200-2206. [CrossRef]

18. Park, S.M.; Choi, J.; Nam, T.G.; Ku, J.M.; Jeong, K. Anti-diabetic effect of 3-hydroxy-2-naphthoic acid, an endoplasmic reticulum stress-reducing chemical chaperone. Eur. J. Pharmacol. 2016, 779, 157-167. [CrossRef]

19. Chen, Z.; Zhu, Q.Y.; Tsang, D.; Huang, Y. Degradation of green tea catechins in tea drinks. J. Agric. Food Chem. 2001, 49, 477-482. [CrossRef]

20. De Araujo, F.F.; de Paulo Farias, D.; Neri-Numa, I.A.; Pastore, G.M. Polyphenols and their applications: An approach in food chemistry and innovation potential. Food Chem. 2020, 338, 127535. [CrossRef]

21. Li, N.; Taylor, L.S.; Ferruzzi, M.G.; Mauer, L.J. Kinetic study of catechin stability: Effects of pH, concentration, and temperature. J. Agric. Food Chem. 2012, 60, 12531-12539. [CrossRef]

22. Labbé, D.; Têtu, B.; Trudel, D.; Bazinet, L. Catechin stability of EGC- and EGCG-enriched tea drinks produced by a two-step extraction procedure. Food Chem. 2008, 111, 139-143. [CrossRef]

23. Rigaku Oxford Diffraction. CrysAlisPro Software System, version 1.171.37.35; Rigaku Corporation: Wroclaw, Poland, 2014.

24. Sheldrick, G.M. Crystal structure refinement with SHELXL. Acta Cryst. C Struct. Chem. 2015, 71, 3-8. [CrossRef]

25. Boultif, A.; Louër, D. Powder pattern indexing with the dichotomy method. J. Appl. Cryst. 2004, 37, 724-731. [CrossRef]

26. Rodríguez-Carvajal, J. Recent advances in magnetic structure determination by neutron powder diffraction. Phys. B Condens. Matter 1993, 192, 55-69. [CrossRef]

27. Buol, X.; Robeyns, K.; Caro Garrido, C.; Tumanov, N.; Collard, L.; Wouters, J.; Leyssens, T. Improving Nefiracetam Dissolution and Solubility Behavior Using a Cocrystallization Approach. Pharmaceutics 2020, 12, 653. [CrossRef]

28. Mahmoud, M.M.; Wallwork, S.C. The Crystal Structure of the 1:1 Complex between Quinol and Urea. Acta Cryst. 1975, B31, 338. [CrossRef]

29. Wiedenfeld, H.; Knoch, F. Zur Kristallstruktur des Theophyllin-Harnstoff-Komplexes. Arch. Pharm. 1986, 319, 654-659. [CrossRef]

30. Preut, H.; Haupt, H.-J. Packing analyses on organometallic compounds. Acta Crystallogr. Sect. A 1981, 37, C93. [CrossRef]

31. Mazzei, L.; Broll, V.; Casali, L.; Silva, M.; Braga, D.; Grepioni, F.; Baltrusaitis, J.; Ciurli, S. Multifunctional urea cocrystal with combined ureolysis and nitrification inhibiting capabilities for enhanced nitrogen management. ACS Sustain. Chem. Eng. 2019, 7, 13369-13378. [CrossRef]

32. Sepúlveda, L.; Ascacio, A.; Rodríguez-Herrera, R.; Aguilera-Carbó, A.; Aguilar, C.N. Ellagic acid: Biological properties and biotechnological development for production processes. Afr. J. Biotechnol. 2011, 10, 4518-4523.

33. Dudek, M.K.; Paluch, P.; Śniechowska, J.; Nartowski, K.P.; Day, G.M.; Potrzebowski, M.J. Crystal structure determination of an elusive methanol solvate-Hydrate of catechin using crystal structure prediction and NMR crystallography. CrystEngComm 2020, 22, 4969-4981. [CrossRef] 